\title{
Loss of $\mathrm{FZO1}$ gene results in changes of cell dynamics in fission yeast
}

\author{
RONGMEI YUAN $^{1 *}$, XIANG DING $^{2 *}$, XIUMEI TAN $^{1 *}$ and YILING HOU ${ }^{1}$ \\ ${ }^{1}$ Key Laboratory of Southwest China Wildlife Resources Conservation (Ministry of Education), \\ College of Life Sciences, China West Normal University; ${ }^{2}$ College of Environmental Science and Engineering, \\ China West Normal University, Nanchong, Sichuan 637009, P.R. China
}

Received February 14, 2020; Accepted September 21, 2020

DOI: $10.3892 /$ ijmm.2020.4752

\begin{abstract}
Mitochondrial fission and fusion dynamics are critical cellular processes, and abnormalities in these processes are associated with severe human disorders, such as Beckwith-Wiedemann syndrome, neurodegenerative diseases, Charcot-Marie-Tooth disease type 6, multiple symmetric lipomatosis and microcephaly. Fuzzy onions protein 1 (Fzolp) regulates mitochondrial outer membrane fusion. In the present study, Schizosaccharomyces pombe (S. pombe) was used to explore the effect of FZO1 gene deletion on cell dynamics in mitosis. The mitochondrial morphology results showed that the mitochondria appeared to be fragmented and tubular in wild-type cells; however, they were observed to accumulate in $f z o 1 \Delta$ cells. The FZO1 gene deletion was demonstrated to result in slow proliferation, sporogenesis defects, increased microtubule (MT) number and actin contraction defects in $S$. pombe. The FZO1 gene deletion also affected the rate of spindle elongation and phase time at the metaphase and anaphase, as well as spindle MT organization. Live-cell imaging was performed on mutant strains to observe three distinct kinetochore behaviors (normal, lagging and mis-segregation), as well as abnormal spindle breakage. The FZOI gene deletion resulted in coenzyme and intermediate metabolite abnormalities as determined via metabolomics analysis. It was concluded that the loss of FZO1 gene resulted in deficiencies in mitochondrial dynamics, which may result in deficiencies in spindle maintenance, chromosome segregation, spindle breakage, actin contraction, and coenzyme and intermediate metabolite levels.
\end{abstract}

Correspondence to: Professor Yiling Hou, Key Laboratory of Southwest China Wildlife Resources Conservation (Ministry of Education), College of Life Sciences, China West Normal University, 1 Shida Road, Nanchong, Sichuan 637009, P.R. China

E-mail: starthlh@126.com

${ }^{*}$ Contributed equally

Key words: mitochondria, FZO1 gene, cell cycle, dynamics, mitosis

\section{Introduction}

Mitochondria are cytoplasmic organelles that are present in most eukaryotic cells, and are comprised of the matrix, the outer membrane (OM) and the inner membrane, which contains cristae that are highly trapped in the inner wall (1). Mitochondria produce ATP via oxidative phosphorylation and play a central role in cell apoptosis (2). In addition to providing energy for cells, mitochondria have other tasks, such as regulating signal transduction, regulating cell death and cell differentiation, and regulating cell growth and cell cycle (2). Mitochondria are constantly dividing, moving and fusing within eukaryotic cells; these dynamics are critical for the normal function of these organelles (3). The kinetic balance of fusion and division plays a critical role in mitochondrial morphology, enabling them to rapidly adapt to the energy demand and maintain their integrity (3). Therefore, the dynamics of mitochondria fission and fusion, and the proteins (which are conserved from yeast to humans) controlling these processes are of major importance; their abnormalities are associated with serious human diseases, including Beckwith-Wiedemann syndrome, neurodegenerative diseases, Charcot-Marie-Tooth disease type 6, multiple symmetric lipomatosis and microcephaly (4).

Membrane fusion is important for the establishment of cell distribution and the morphology of mitochondrial chambers (5). When fission is dominant, mitochondria are in the form of isolated dots, and when fusion is dominant, mitochondria are in the form of interconnected filaments (6). Conserved dynamin-related proteins (Drps) regulate mitochondrial dynamics (7). Based on the analysis of spermatogenesis defects in Drosophila mutants, the $F Z O$ gene for mitochondrial fusion was identified (8). The discovery of FZO homologues in yeasts, nematodes and mammals defined a novel family of high molecular weight GTPases with multiple domains (8). Fuzzy onions protein 1 (Fzolp) controls mitochondrial OM fusion in various cell types and organisms (9).

Cell replication involves a series of highly evolutionary conserved and regulated complex processes referred to as the cell cycle (10). Schizosaccharomyces pombe (S. pombe), termed fission yeast, is a unicellular organism that possesses numerous cell cycle characteristics similar to those in mammalian cells, and which can easily be genetically manipulated (11). It is an important model cell for investigating checkpoint controls and the cell 
cycle (12). In the present study, S. pombe was used to explore the effect of FZOI gene deletion on cell dynamics in mitosis.

\section{Materials and methods}

S. pombe strains construction. All strains used in the present study, wild-type and mutant, were donated by Associate Professor Phong Tran (University of Pennsylvania). A small patch of HY $3447 \mathrm{~h}^{+} / \mathrm{h}^{-}$cells and equivalent patch of wild-type $\mathrm{PT} \mathrm{h}^{+} / \mathrm{h}^{-}$cells that had different fluorescent protein markers were added onto a mating plate [Edinburgh minimal medium without nitrogen (EMM-N); Formedium Ltd.; diameter, $5 \mathrm{~mm}$ ] and blended well. Cells on the mating plate were incubated at $25^{\circ} \mathrm{C}$ for $24 \mathrm{~h}$. A patch of cells from the sporulation/mating plate were added to glusulase suspension (100 $\mu \mathrm{l}$; Shanghai Yuanye Bio-Technology Co., Ltd.) and incubated overnight at room temperature. Sterile water was used to wash the glusulase and a microscope was used to verify that all cells were hydrolyzed. Diluted cells $(10 \mu \mathrm{l})$ were collected and spread on a YE5S-G418 $(0.225 \mathrm{mg} / \mathrm{ml}$ G418; Formedium Ltd.) plate evenly. Colonies typically appeared following incubation for 3 days at $25^{\circ} \mathrm{C}$. Monoclones which had appropriate markers were identified and isolated under a fluorescence microscope (13). In the donated strains, constructs expressing red fluorescent protein-cytochrome $c$ oxidase 4 (RFP-Cox4) had been integrated into the leu 2 locus, and constructs expressing mCherry-tubulin $\alpha 2$ (Atb2), histone $\mathrm{H} 3$ (Hht2)-green fluorescent protein (GFP), actin (pACT1)-LifeAct-GFP and GFP-Atb2 were integrated into the leu1 locus. All strains used in the present study are listed in Table I.

Cell proliferation. Cells were transferred from YE5S solid medium (Formedium Ltd.) to YE5S liquid medium (Formedium Ltd.), cultured in a cultivation shaker (Shanghai Bluepard Instruments Co., Ltd.) at $25^{\circ} \mathrm{C}$ for $24 \mathrm{~h}$ for cell activation. When the optical density (OD) ${ }_{595}$ of wild-type and $f_{z o l} \Delta$ cells reached $0.5-0.8$, cells were diluted to an $\mathrm{OD}_{595}$ of 0.1 . Then, cells were cultured in a cultivation shaker at $25^{\circ} \mathrm{C}$ and the $\mathrm{OD}_{595}$ was determined every $2 \mathrm{~h}$ using a microplate reader (Thermo Fisher Scientific, Inc.).

Observation of sporogenesis. A patch of HY $3447 \mathrm{~h}^{+}$cells and an equivalent patch of $3447 \mathrm{~h}^{-}$cells were collected, added to a mating plate (EMM-N; diameter, $5 \mathrm{~mm}$ ) and blended well. The mating plate was incubated for $24 \mathrm{~h}$ at $25^{\circ} \mathrm{C}$. A patch of cells was collected during the sporulation/mating plate to observe the formation of zygotes. The method for observing wild-type cell sporulation was the same as for HY 3447 cells. During the observation of ascospores, 500 cells without damage to the cell wall were selected randomly for image collection to ensure that spores did not overflow and cause analysis errors. Then, the proportion of cells that produced 2, 3 or 4 spores was calculated, with three replicates performed. The total number of cells analyzed in each group was 1,500 (8).

Microscopy. The camera used to capture ascospores images was an Olympus DP72 (Olympus Corporation) and the microscope was an Olympus BX51 (magnification, x1,000; Olympus Corporation). The software used to capture ascospores images was cellSens Entry (Olympus Corporation). Live-cell imaging was conducted at $25^{\circ} \mathrm{C}$. A Photometrics CoolSNAP HQ2 CCD camera (Teledyne Photometrics) and a spinning-disc confocal microscope (Olympus Corporation) with a Nikon PlanApo x100/1.40 NA objective (Nikon Corporation) were used for imaging of living cells (14). MetaMorph 7.5 (Molecular Devices, LLC) was used to analyze all images. Images were acquired at $60-\mathrm{sec}$ intervals across a total time of $90 \mathrm{~min}$, with an exposure of 300-500 msec for GFP/mCherry fluorescence acquisition in 11 optical sections of $0.5-\mu \mathrm{m}$ distance. Microtubules (MTs) were observed for $8 \mathrm{~min}$; the maximum number of MTs in each cell was used as the final MT number, and the maximum MT length of each MT was used as the final MT length. Analysis of energy metabolites. Cells were cultured in YE5S medium for 3 days at $25^{\circ} \mathrm{C}$. The cells were washed three times with cold PBS and collected in a $1.5-\mathrm{ml}$ centrifuge tube, and then frozen in liquid nitrogen and stored at $-80^{\circ} \mathrm{C}$ following centrifugation at $3,000 \times \mathrm{g}$ and $4^{\circ} \mathrm{C}$ for $5 \mathrm{~min}$. The collected cells were sent to Shanghai Applied Protein Technology Co., Ltd. to be analyzed for metabolomics via liquid chromatography-mass spectrometry (LC-MS).

Data analysis. Bar graphs and line graphs were expressed using mean $\pm \mathrm{SD}$, other data were presented as box plots, and SPSS 17 software (SPSS, Inc.) was used to analyze significant differences between the control group and the experimental group by one-way ANOVA. $\mathrm{P}<0.05$ was considered to indicate a statistically significant difference. All plots were analyzed using Kaleidagraph 4.0 (http://www.synergy.com). Box plots present the median and interquartile range, and includes all individual data, with any outliers displayed as a single point. The number of repeats for each experiment is indicated in the corresponding figure legend. The fluorescence ratio was used in MetaMorph 7.5 to reduce the error in fluorescence detection.

\section{Results}

Effects of FZO1 gene deletion on mitochondrial morphology, cell growth and the number and morphology of ascospores. The mitochondrial morphology analysis showed that the mitochondria (visualized by RFP-Cox4) appeared to be fragmented and tubular in wild-type cells, while they showed a state of accumulation in fzol $\Delta$ cells (Fig. 1A). The cell proliferation results indicated that there was little difference in the proliferation rates of wild-type and fzol $\Delta$ cells at $25^{\circ} \mathrm{C}$ between $0-6 \mathrm{~h}$. After $6 \mathrm{~h}$, the proliferation rate of wild-type cells increased, while that of fzol $\Delta$ cells exhibited relatively slow growth in comparison. At $12 \mathrm{~h}$, the optical density (OD) ${ }_{595}$ of wild-type cells had reached $0.625 \pm 0.01$, but the $\mathrm{OD}_{595}$ of $f z o l \Delta$ cells was only $0.422 \pm 0.05$, which was significantly reduced compared with the wild-type cells $(\mathrm{P}<0.05$; Fig. $1 \mathrm{~B})$. The results indicated that $\mathrm{FZOl}$ gene deletion reduced the proliferation rate of $S$. pombe to a certain extent. The number of MTs in wild-type and fzol $\Delta$ cells at mitotic interphase were subsequently analyzed $(\mathrm{n}=20$; Fig. 1C and D). The results showed that $35 \pm 7.64,55 \pm 8.26$ and $20 \pm 2.89 \%$ of wild-type cells exhibited three, four and five MTs, respectively, whereas $6.67 \pm 2.89,31.67 \pm 2.89,60 \pm 5.00$ and $1.66 \pm 2.89 \%$ of $f z o l \Delta$ cells exhibited three, four, five and six MTs, respectively ( $n=20$; Fig. 1D). There was a significant difference in the frequency of cells with three and four MTs between wild-type and fzol $\Delta$ cells $(\mathrm{P}<0.05)$. Of note, the 
Table I. List of strains.

\begin{tabular}{|c|c|c|}
\hline Strain & Genotype & Figure \\
\hline PT 286 & Wt:h- & NA \\
\hline PT 287 & Wt:h+ & NA \\
\hline PT 917 & Wt: mCherry-Atb2 h- & NA \\
\hline PT 735 & Wt: GFP-Atb2 h+ & NA \\
\hline PT 3850 & Wt: pACT1-LifeAct-GFP: LEU1 h+/h- & NA \\
\hline PT 2167 & Wt: Hht2-GFP: URA4 h+ & NA \\
\hline PT 1683 & Wt: RFP-Cox4 h? & NA \\
\hline HY 1 & Wt: Hht2-GFP: URA4/mCherry-Atb2 h+/h- & Figs. 2 and 3 \\
\hline HY 2 & Wt: KanR pACT1-LifeAct-GFP: LEU1/mCherry-Atb2 h+/h- & Fig. 4 \\
\hline HY 3 & Wt: KanR GFP-Atb2/RFP-Cox4 h+/h- & Fig. 1 \\
\hline HY 3447 & fzol $\Delta: \mathrm{KanR} \mathrm{h}+\mathrm{h}-$ & NA \\
\hline HY $3447-1$ & fzol $\Delta:$ KanR Hht2-GFP: URA4/mCherry-Atb2 h? & Figs. 2 and 3 \\
\hline HY $3447-2$ & fzol $\Delta:$ KanR pACT1-LifeAct-GFP: LEU1/mCherry-Atb2 h? & Fig. 4 \\
\hline HY $3447-3$ & fzol $1 \Delta$ : KanR GFP-Atb2/RFP-Cox4 h? & Fig. 1 \\
\hline
\end{tabular}

Atb2, tubulin $\alpha 2$; Cox 4, cytochrome $c$ oxidase 4; Hht2, histone H3; GFP, green fluorescent protein; KanR, kanamycin resistance; LEU1, 3-isopropylmalate dehydratase; NA, not applicable; pACT1, actin; RFP, red fluorescent protein; URA4, dihydroorotase; Wt, wild-type.

number of wild-type and fzol $\Delta$ cells with five MTs was highly significantly different $(\mathrm{P}<0.01)$. Statistical analysis of MT length in mitotic interphase cells showed that the average MT lengths in wild-type and fzol $\Delta$ cells were $5.13 \pm 1.44$ and $4.89 \pm 1.63 \mu \mathrm{m}$, respectively, which were not significantly different $(n=20)$ (Fig. 1E). The results indicated that loss of FZO1 resulted in an increase in the number of MTs in cells without a notable effect on MT length compared with wild-type cells.

The number of ascospores produced by wild-type and fzol $\Delta$ cells were subsequently analyzed (Fig. $1 \mathrm{~F}$ and $\mathrm{G}$ ). The results showed that $0.3,0.5$ and $99.2 \%$ of wild-type cells produced two, three and four ascospores, respectively, whereas $0.5,4.9$ and $94.5 \%$ of fzol $\Delta$ cells produced two, three and four ascospores, respectively $(n=1500$; Fig. 1F). The number of $f z o l \Delta$ cells with two and three spores were significantly increased compared with wild-type cells $(\mathrm{P}<0.05)$, while there was no notable difference in ascospore morphology between wild-type and fzol $\triangle$ cells, which suggested that the FZOI gene and its encoded protein affected the quantity of ascospores of $S$. pombe without affecting spore morphology (Fig. 1G).

Effect of FZO1 gene deletion on spindle and cell length during cell division. There are three different elongation stages of the mitotic spindle, corresponding to different stages of mitosis (15). The spindle pole bodies (SPBs) can regulate the mitotic spindle for chromosomal separation. At the same time, SPBs also regulate the astral MTs, and their functions in nuclear and spindle localization are similar to interphase MTs (15). To gain insight on the effect of FZO1 gene deletion on spindle assembly, the spindle assembly dynamics were analyzed by live-cell imaging in fission yeast fzol $\Delta$ cells expressing mCherry-Atb2 and Hht2-GFP compared with wild-type cells. In wild-type cells, three-phase spindle elongation dynamics were observed, specifically prophase, metaphase, and anaphase A (chromatid separation) and B (spindle elongation). There were some abnormalities observed in fzol $\Delta$ cells. Spindle length analysis revealed delayed or failed spindle elongation in fzol $\Delta$ cells $(n=20$; Fig. 2A and B). Analysis of spindle elongation time showed that the $f z o 1 \Delta$ cells eventually elongated with a delayed transition from metaphase to anaphase A by $3 \mathrm{~min}$, which was significantly different compared with wild-type cells $(\mathrm{P}<0.05$; $\mathrm{n}=20$; Fig. 3C), and with a delayed elongation of $4.6 \mathrm{~min}$ during anaphase $\mathrm{B}$, which was strongly significantly different compared with wild-type cells $(\mathrm{P}<0.01 ; \mathrm{n}=20$; Fig. 3E). Cell length analysis of wild-type and fzol $\Delta$ cells showed that the cell lengths of wild-type cells at the spindle formation, prophase-metaphase transition, metaphase-anaphase transition, anaphase-telophase transition and end points during mitosis were $12.86 \pm 1.30,12.99 \pm 1.23,13.22 \pm 1.26,13.40 \pm 1.25$ and $8.46 \pm 1.07 \mu \mathrm{m}$, respectively, whereas those of fzol $\Delta$ cells were $13.48 \pm 1.45,13.64 \pm 1.42,13.79 \pm 1.44,13.94 \pm 1.45$ and $8.35 \pm 0.73 \mu \mathrm{m}$, respectively $(\mathrm{n}=20$; Fig. $2 \mathrm{C}-\mathrm{H})$. There was no significant difference in cell length between the two groups.

Effects of FZO1 gene deletion on spindles and chromosomes during cell division. mCherry-Atb2 and Hht2-GFP were also used to monitor spindle elongation and chromosome segregation dynamics in cell mitosis. First, spindle and chromosome dynamics were analyzed during prophase and metaphase of cell division. The spindle of wild-type cells elongated at $0.23 \pm 0.09 \mu \mathrm{m} / \mathrm{min}$ during prophase, with a prophase duration of $3.80 \pm 1.01 \mathrm{~min}$ prior to reaching a steady-state metaphase; the spindle of wild-type cells elongated at $0.13 \pm 0.05 \mu \mathrm{m} / \mathrm{min}$ during metaphase with a duration of $14.75 \pm 3.43 \mathrm{~min}$. In contrast, the spindle of $f z o l \Delta$ cells elongated at $0.26 \pm 0.12 \mu \mathrm{m} / \mathrm{min}$ during prophase, with a duration of $4.00 \pm 0.92 \mathrm{~min}$, and the spindle elongated at $0.11 \pm 0.04 \mu \mathrm{m} / \mathrm{min}$ during metaphase with a duration of $17.55 \pm 4.98 \mathrm{~min}$. The duration of metaphase was significantly different between wild-type and fzol $\Delta$ cells $(\mathrm{P}<0.05 ; \mathrm{n}=20$; Fig. 3A-D). In addition, the spindle of wild-type cells elongated at $0.56 \pm 0.07 \mu \mathrm{m} / \mathrm{min}$ during anaphase, with a duration of $16.05 \pm 2.26 \mathrm{~min}$, whereas the spindle of $f z o l \Delta$ cells elongated 
A
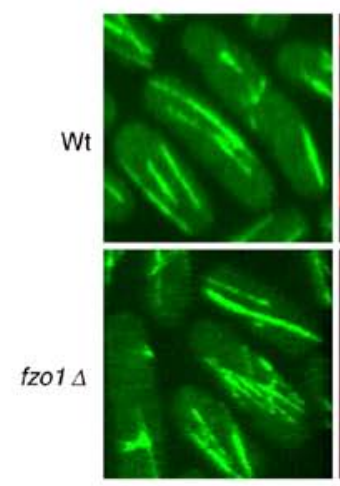

C

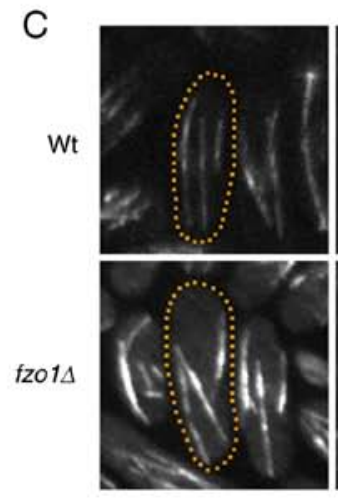

E

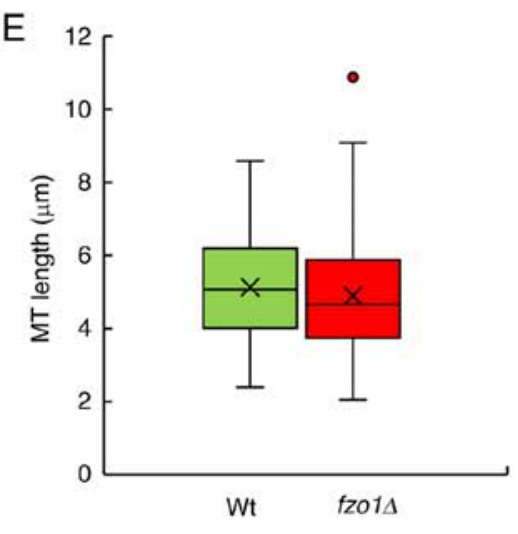

G

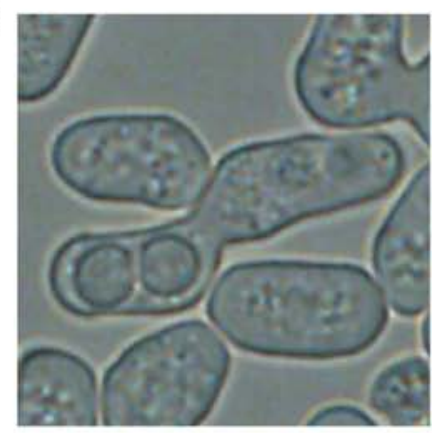

Two spores

RFP-COx4
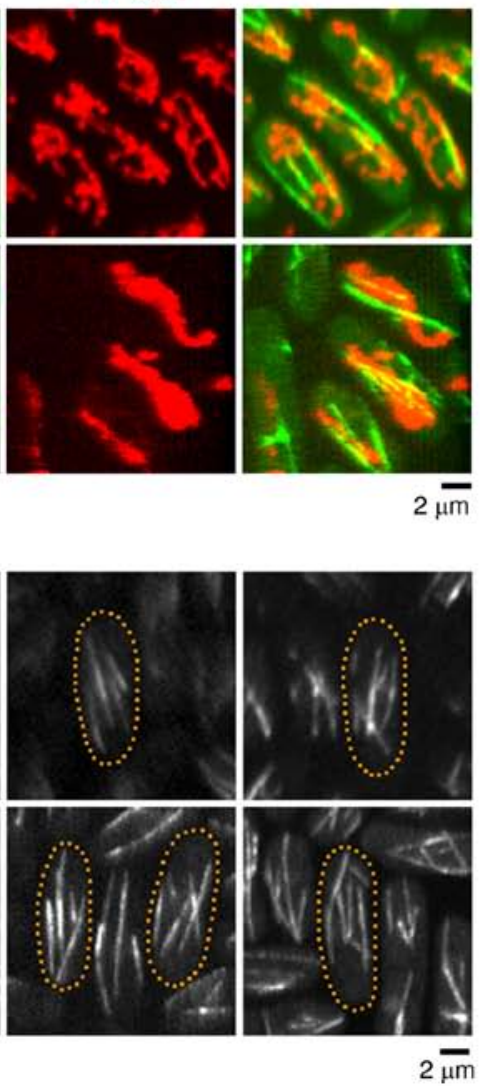

$2 \overline{\mu m}$

\section{F}
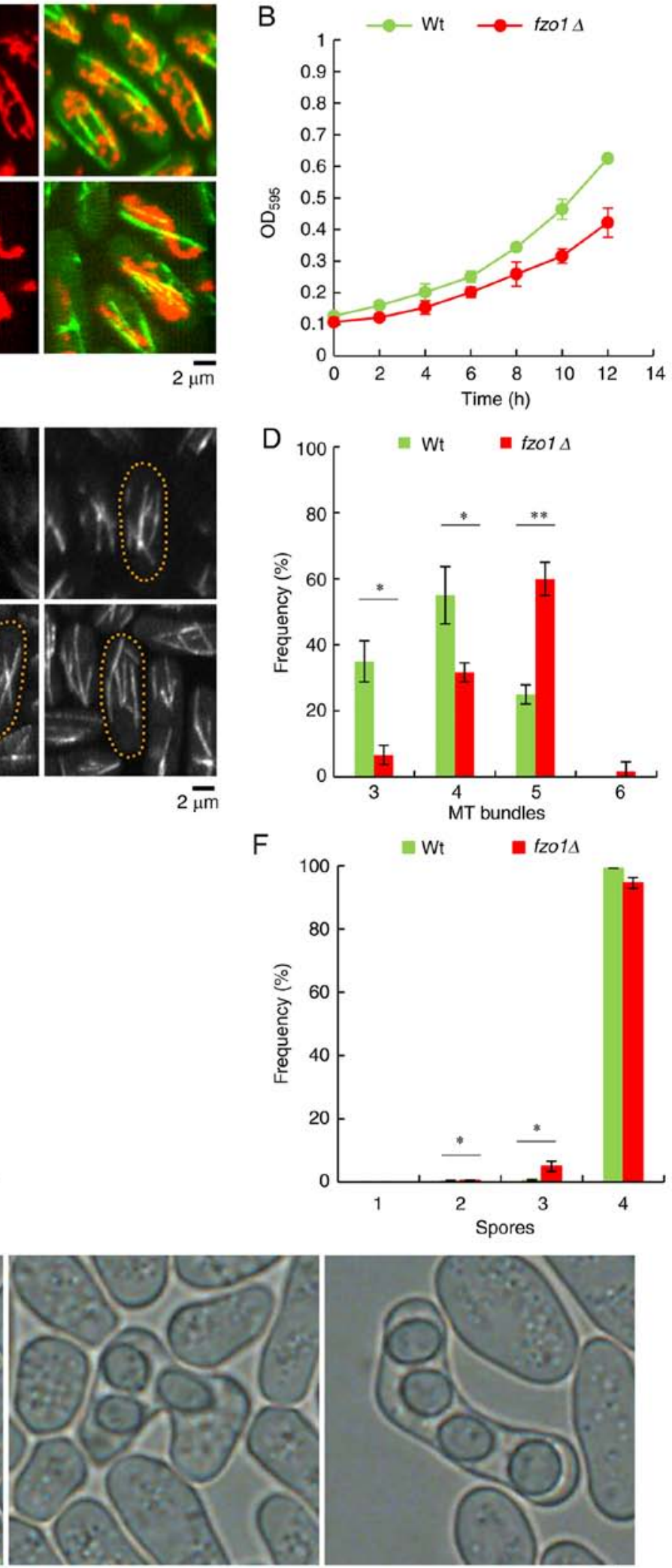

Three spores

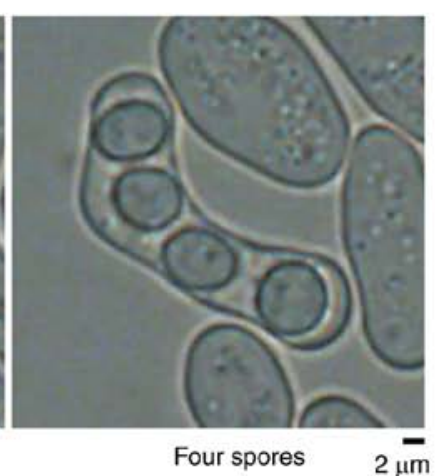

Figure 1. Effect of FZO1 gene deletion on mitochondrial morphology, cell growth, and numbers of MT and ascospores. (A) Mitochondria morphology (RFP-Cox4) and MT bundles (GFP-Atb2) in Wt and fzol $\Delta$ cells. (B) Growth curves of Wt and $f$ zol $\Delta$ cells cultured at $25^{\circ} \mathrm{C}$. Data are presented as the mean $\pm \mathrm{SD}$ ( $\mathrm{n}=3$ experimental repeats). (C) MT morphology of Wt cells and fzol $\Delta$ cells at mitotic interphase. Example images of Wt cells with three, four and five MTs, respectively, are presented from left to right; $f$ zol $\Delta$ cells with three, four, five and six MTs are also presented. (D) Number of MTs in Wt cells and $f z o 1 \Delta$ cells at the mitotic interphase ( $\mathrm{n}=20$ cells). (E) Length of MTs in Wt and $f z o 1 \Delta$ cells at the mitotic interphase ( $\mathrm{n}=80 \mathrm{MTs}$ ). (F) Spore number in Wt and $f z o 1 \Delta$ cells ( $\mathrm{n}=1,500$ cells). (G) Morphology of ascospores in $f z o 1 \Delta$ cells. Example images of $f z o 1 \Delta$ cells with two, three and four ascospores, respectively, from left to right. ${ }^{*} \mathrm{P}<0.05,{ }^{* *} \mathrm{P}<0.01$. fzo, fuzzy onions; GFP-Atb2, green fluorescent protein-tubulin $\alpha 2$; MT, microtubule; OD, optical density; RFP-Cox4, red fluorescent protein-cytochrome $c$ oxidase 4; Wt, wild-type. 
A

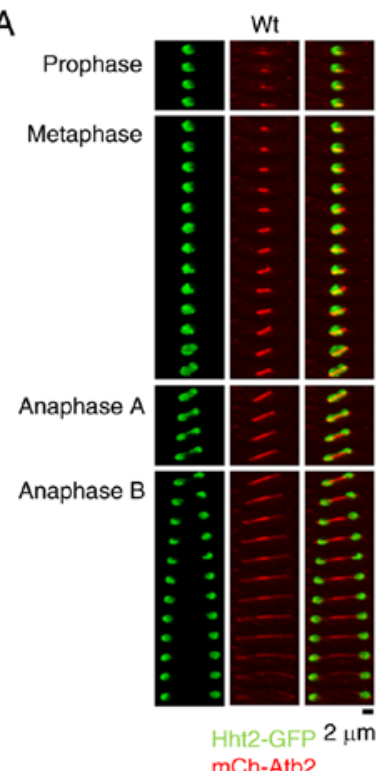

B

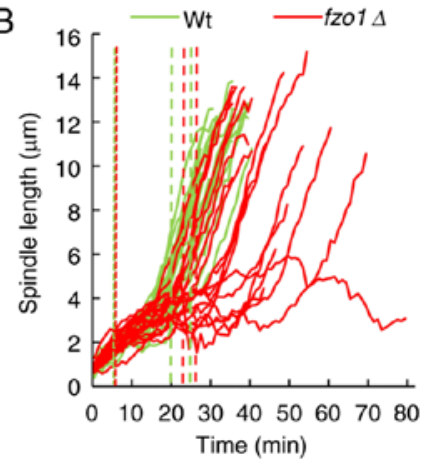

$\mathrm{D}$

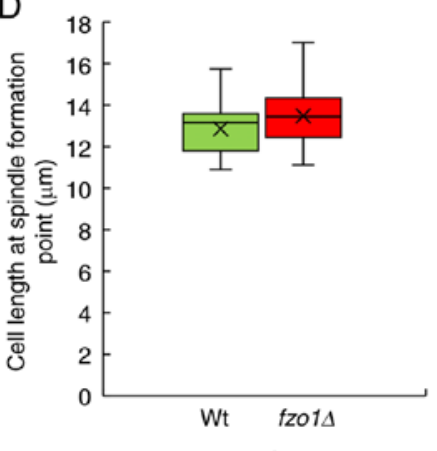

G

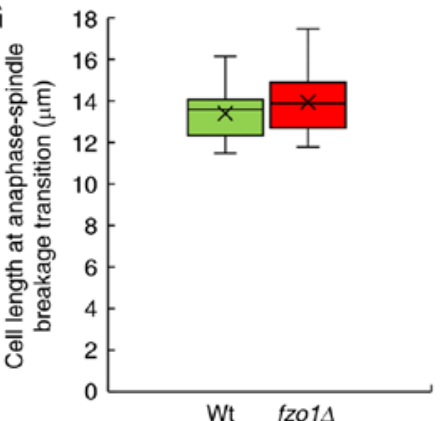

$f z 01 \Delta(\mathrm{a})$

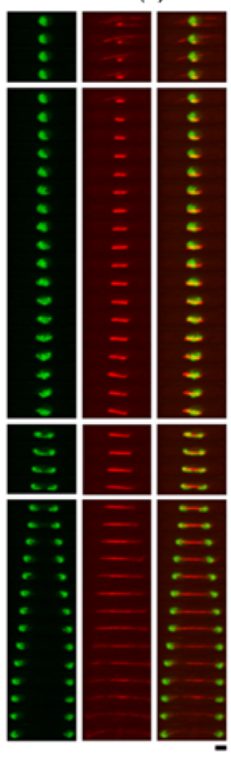

$2 \mu \mathrm{m}$

C

E
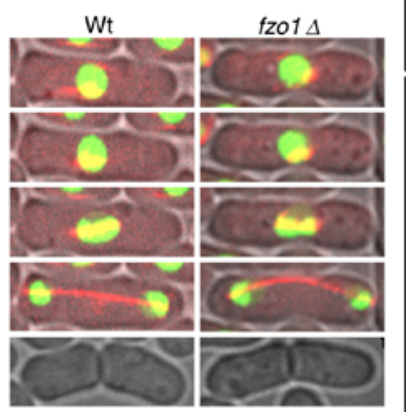

$2 \mu \mathrm{m}$
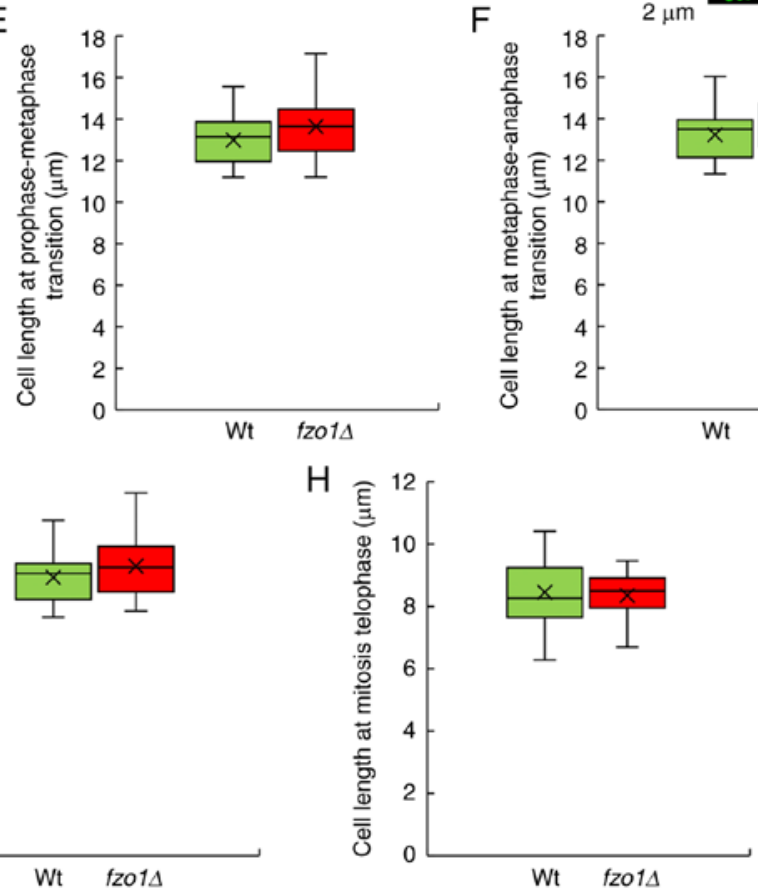

fzo1 $\Delta$ (c)
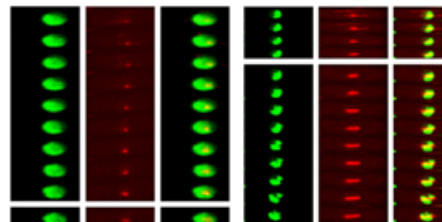

$\begin{array}{lll} & & \vdots \\ \vdots & \vdots & \vdots \\ \vdots & \vdots & \vdots\end{array}$

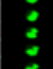

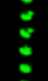

$\approx$

$\div=$

$: 1=$

,
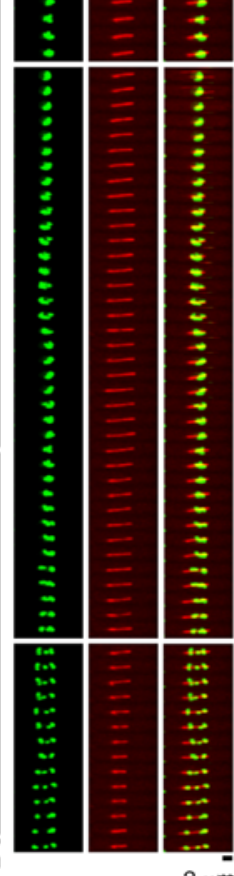

$F$

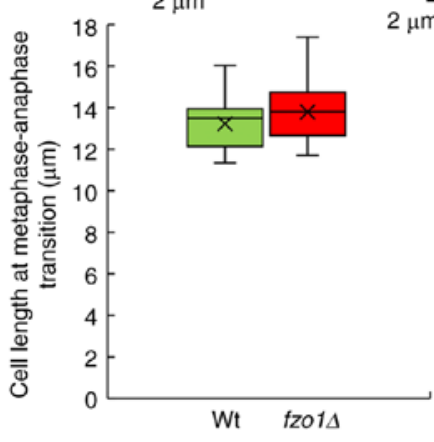

Figure 2. Effect of $F Z O 1$ gene deletion on spindle and cell length during cell mitosis. (A) Spindle and chromosome dynamics of Wt cells and $f z o l \Delta$ cells during whole cell mitosis. Wt cells exhibited normal mitosis, $f z o l \Delta$ cells exhibited (a) metaphase prolongation, (b) anaphase prolongation, (c) anaphase delay and (d) chromosome mis-segregation. (B) Spindle elongation in Wt and $f z o 1 \Delta$ cells during cell mitosis. ( $\mathrm{n}=20$ cells). Green and red dotted lines indicate the transitions during cell mitosis in Wt cells and fzol $\Delta$ cells, respectively. The dotted lines in the figure indicate, from left to right, the transitions between prophase and metaphase, metaphase and anaphase, and anaphase A and anaphase B, respectively. (C) Cell morphology of Wt and fzol $\Delta$ cells at, from top to bottom, spindle formation, prophase-metaphase transition, metaphase-anaphase transition, anaphase-telophase transition and the end point of mitosis. Length of Wt and fzol $\Delta$ cells at (D) spindle formation, (E) prophase-metaphase transition, (F) metaphase-anaphase transition, (G) anaphase-spindle breakage transition and (H) mitosis telophase ( $\mathrm{n}=20$ cells). fzo, fuzzy onions; Hht2-GFP, histone H3-green fluorescent protein; mCherry-Atb2, mCherry-tubulin $\alpha 2$; Wt, wild-type. 


\section{A}

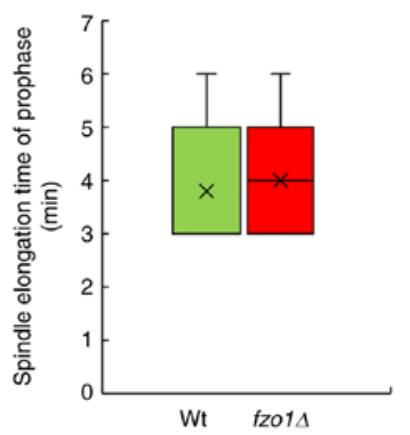

$\mathrm{D}$

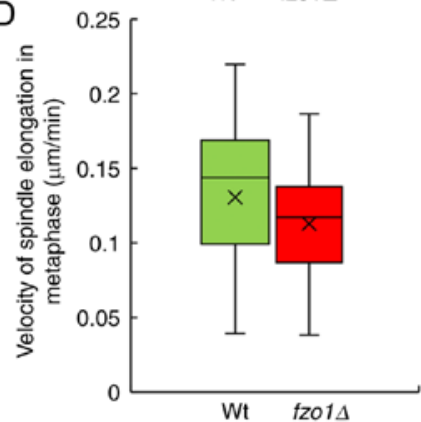

G

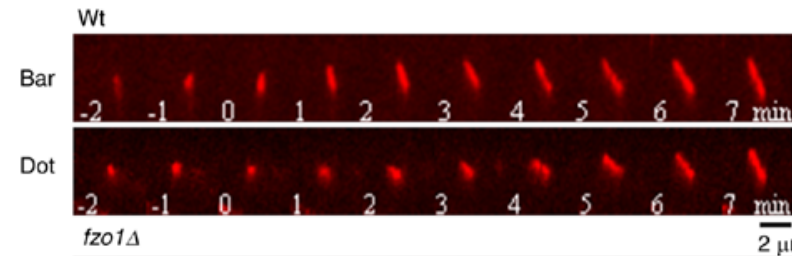

$$
\text { Bar }{ }_{2}
$$

Dot

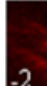

Mono
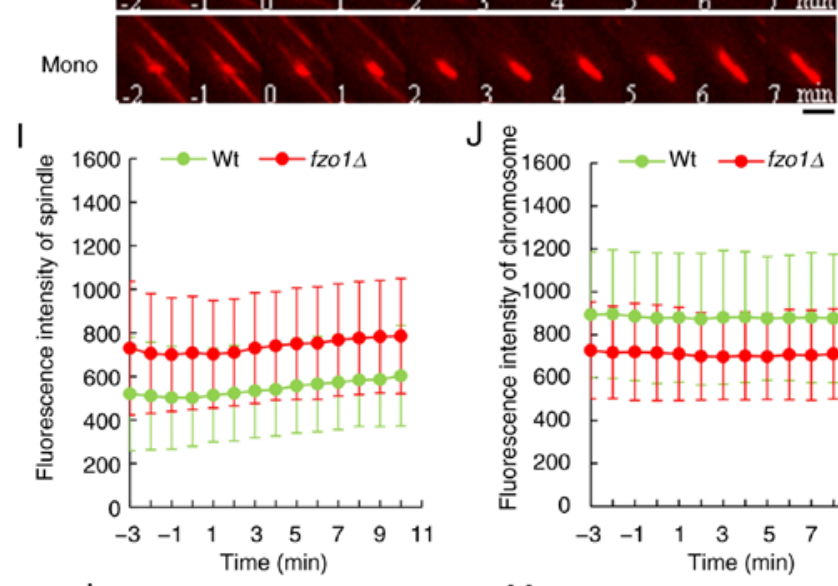

$\mathrm{L}$

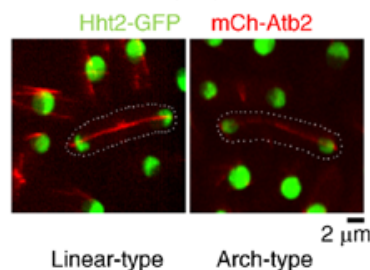

B
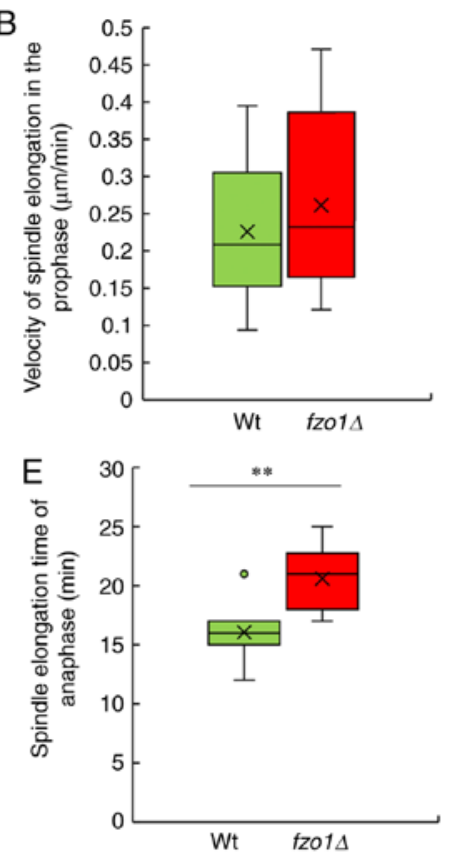

$\mathrm{H}$

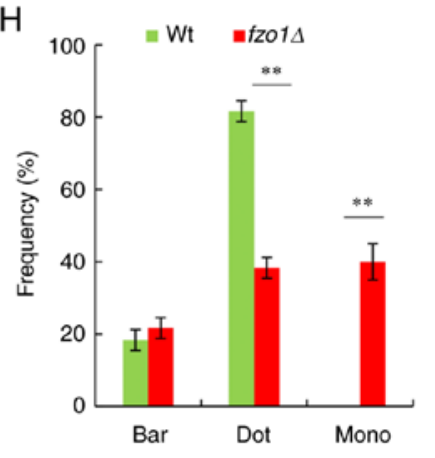

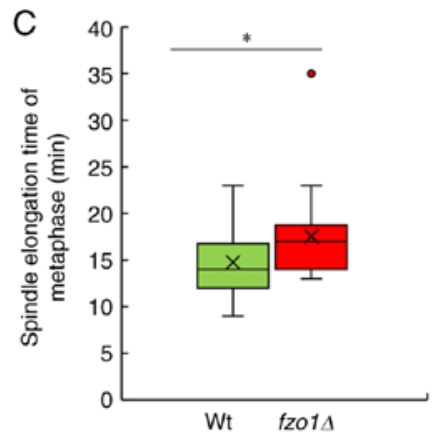
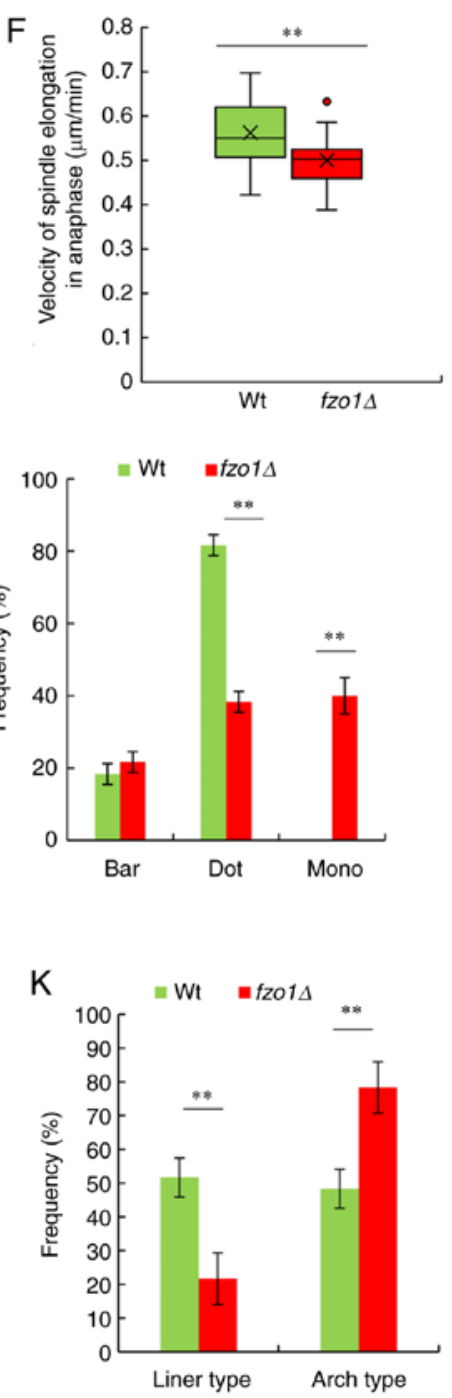

Figure 3. Effect of FZOI gene deletion on the spindle and chromosome in mitosis. (A) Spindle elongation time of prophase (n=20 cells). (B) Velocity of spindle elongation in prophase $(\mathrm{n}=20$ cells), (C) Spindle elongation time of metaphase $(\mathrm{n}=20$ cells). (D) Velocity of spindle elongation in metaphase ( $\mathrm{n}=20$ cells). (E) Spindle elongation time of anaphase ( $\mathrm{n}=20$ cells). (F) Spindle elongation velocity in anaphase ( $\mathrm{n}=20$ cells). (G) Morphology of spindle formation types in Wt and fzol $\Delta$ cells; 0 min indicates the complete disassembly of cytoplasmic interphase microtubules. (H) Frequency of spindle formation types in Wt and $f z o 1 \Delta$ cells ( $\mathrm{n}=20$ cells). (I) Spindle fluorescence intensity in Wt and $f z o 1 \Delta$ cells at prophase and metaphase ( $\mathrm{n}=20$ cells); 0 min is the prophase-metaphase transition point. (J) Chromosome fluorescence intensity in Wt and $f z o l \Delta$ cells at prophase and metaphase ( $\mathrm{n}=20$ cells); 0 min is the prophase-metaphase transition point. (K) Frequency of spindle break types in Wt and fzol $\Delta$ cells ( $\mathrm{n}=20$ cells). (L) Morphology of spindle break types in yeast cells at anaphase. (M) Morphology of chromosome segregation types in yeast cells at anaphase. Wt cells exhibited normal chromosome segregation; fzol $\Delta$ cells exhibited lagging and mis-segregation of chromosomes. ${ }^{*} \mathrm{P}<0.05,{ }^{* * *} \mathrm{P}<0.01$. fzo, fuzzy onions; Hht2-GFP, histone H3-green fluorescent protein; mCherry-Atb2, mCherry-tubulin $\alpha 2$; Wt, wild-type. 
at $0.50 \pm 0.06 \mu \mathrm{m} / \mathrm{min}$ with a duration of $20.60 \pm 2.48 \mathrm{~min}$ $(\mathrm{P}<0.01 ; \mathrm{n}=20$; Fig. $3 \mathrm{E}$ and $\mathrm{F})$. Both of these values were significantly different between wild-type and fzol $\Delta$ cells.

Spindle MT organization was markedly different in fzol $\Delta$ cells compared with wild-type cells $(\mathrm{n}=20$; Fig. $3 \mathrm{G})$. In wild-type cells, mitosis and the disintegration of intercellular MTs occurred simultaneously. In order to standardize the measurements of mitotic time, the starting time of mitosis was defined as 0 min. Only $21.67 \pm 2.89 \%$ of $f z o l \Delta$ cells exhibited bars at $0 \mathrm{~min}$; the remainder exhibited delayed formation of the bipolar spindle, with a frequency of spindle dots $(38.33 \pm 2.89 \%)$. Of note, $40 \pm 5 \%$ of $f z o l \Delta$ cells exhibited transient MT protrusions, termed monopolar spindles $(n=20$; Fig. $3 \mathrm{H})$. On the contrary, in wild-type cells, at $0 \mathrm{~min}$, the assembly of MT bars $(81.67 \pm 2.89 \%$ of cells) or dots $(18.33 \pm 2.89 \%$ of cells) was reliably observed. There were significant differences in the frequency of dots and monopolar spindles between wild-type and $f z o 1 \Delta$ cells $(\mathrm{P}<0.01)$. The MT rapidly transforms into a bar (100\% of cells), indicative of a bipolar spindle. No wild-type cells exhibited monopolar spindles. The results showed that spindle MT organization was markedly affected by $\mathrm{FZOI}$ gene deletion.

Studies have shown that there is a clear correlation between the intensity of a fluorescent protein and expression of the other gene in the construct, and that fluorescent intensity can indirectly reflect the expression level of the attached gene product $(16,17)$. Analysis of fluorescence intensity of the spindle at prophase and metaphase showed that the fluorescence intensity of the spindle in fzol $\Delta$ cells was notably stronger compared with in wild-type cells, whereas fluorescence intensity of the chromosome at prophase and metaphase was notably weaker in $f z o l \Delta$ cells compared with in wild-type cells $(n=20$; Fig. 3I and J), which indicated that the gene expression levels of the spindle (as indicated by tubulin $\alpha 2$ ) were upregulated and those of the chromosome (as indicated by histone $\mathrm{H} 3$ ) were downregulated following $\mathrm{FZOI}$ gene deletion.

The fidelity of chromosome segregation depends substantially on the appropriate attachment of MTs to the centromere in metaphase (15). Chromosome segregation depends on the assembly of spindles, which are MT-based structures that effectively capture and separate sister chromatids during cell mitosis. There is association between mutations that change the length of metaphase stable spindles and chromosome segregation defects (15). Live-cell imaging was performed on strains expressing mCherry-Atb2 and Hht2-GFP. It was observed that in wild-type cells, the spindle broke in the form of linear-type (51.67 $\pm 5.77 \%)$ and arch-type $(48.33 \pm 5.77 \%)$ structures; however, in fzol $\Delta$ cells, the frequency of the two forms were $21.67 \pm 7.64$ and $78.33 \pm 7.64 \%$, respectively $(\mathrm{P}<0.01$, $\mathrm{n}=20$ ) (Fig. 3K and L), which were both significantly different compared with wild-type cells. The results showed that the loss of FZO1 gene also led to abnormal spindle breakage. There were three distinct chromosome behaviors observed: Normal (100\% of wild-type, $65 \%$ of $f z o l \Delta$ ), the chromosomes were separated to opposite poles during anaphase; lagging (30\%), the chromosomes were segregated to one pole wrongly, but the chromosome corrected and separated to the opposite poles eventually; and mis-segregation (5\%), the chromosomes stayed at one pole and never separated to opposite poles (Fig. 3M).
The results indicated that the loss of $\mathrm{FZOI}$ contributed to metaphase spindle length maintenance deficiencies and chromosome segregation deficiencies.

Effects of FZOI gene deletion on actin in mitosis. mCherry-Atb2 and pACT1-LifeAct-GFP were used to detect actin contraction dynamics in cell mitosis. In rod-shaped division, the cell only grows at the top of the cell, and its diameter remains unchanged (18). Therefore, when the cell stops growing, the final cell size can be quantified by measuring the cell length during mitosis. To investigate the impact of FZOI gene deletion on cell size during mitosis, the length from the splitting point to the cell wall was measured. The results showed that the distance in wild-type and $f z o l \Delta$ cells was $6.68 \pm 0.88$ and $6.76 \pm 0.85 \mu \mathrm{m}$, respectively (Fig. 4B). The results showed that $\mathrm{FZOI}$ gene deletion had no significant effect on cell size during mitosis. The morphology of actin did not notably change in the two groups (Fig. 4A); however, during mitosis, the contraction rate of actin varied between wild-type and $f z o l \Delta$ cells. The contraction time of actin in most mutant cells was the same as that in wild-type cells, but it took longer for a small portion of the mutant cells to complete contraction (Fig. 4C and D). Statistical analysis of actin contraction rates showed that the actin contraction rate in wild-type and fzol $\Delta$ cells was $0.11 \pm 0.01$ and $0.10 \pm 0.02 \mu \mathrm{m} / \mathrm{min}$, respectively, which was significantly different $(\mathrm{P}<0.01 ;$ Fig. 4E). The fluorescence intensity of actin during mitosis was increased in wild-type compared with in fzol $\Delta$ cells during both anaphase and telophase (Fig. 4F and G).

Effect of FZO1 gene deletion on coenzymes in energy metabolism. The tricarboxylic acid cycle, glycolysis and oxidative phosphorylation pathways are the central pathways of cell energy production (19). In order to further investigate energy metabolism in fzol $\Delta$ cells, coenzymes and energy metabolites involved in in the tricarboxylic acid cycle, glycolysis and oxidative phosphorylation were detected via LC-MS. The results showed that the relative contents of nicotinamide adenine dinucleotide phosphate (NADPH) and nicotinamide adenine dinucleotide $\left(\mathrm{NAD}^{+}\right)$in the wild-type cells were $16.37 \pm 0.26$ and $25.85 \pm 0.08$, respectively, while those in $f z o 1 \Delta$ cells were $15.24 \pm 0.16$ and $25.45 \pm 0.03$, respectively, which were significantly different $(\mathrm{P}<0.01$; Fig. $5 \mathrm{~A}$ and $\mathrm{B})$. The relative contents of nicotinamide adenine dinucleotide phosphate $\left(\mathrm{NADP}^{+}\right)$ and acetyl coenzyme A (acetyl-CoA) in wild-type cells were $23.44 \pm 0.37$ and $19.68 \pm 0.50$, respectively, while those in $f z o l \Delta$ cells were $22.38 \pm 0.24$ and $18.20 \pm 0.03$, respectively, which again were significantly different $(\mathrm{P}<0.05$; Fig. $5 \mathrm{C}$ and $\mathrm{D})$. However, there were not significant differences between the two groups in the relative contents of intermediate metabolites such as flavin mononucleotide and thiamine pyrophosphate. The results indicated that $F Z O 1$ gene deletion affected the relative contents of NADPH, $\mathrm{NAD}^{+}, \mathrm{NADP}^{+}$and acetyl-CoA, interfering with the tricarboxylic acid cycle, glycolysis and oxidative phosphorylation.

Effect of FZO1 gene deletion on intermediate metabolites in energy metabolism. Analysis of intermediate metabolites in energy metabolism showed that the relative contents of L-malic acid, isocitrate and citrate(1-) in the wild-type cells 


\section{A}

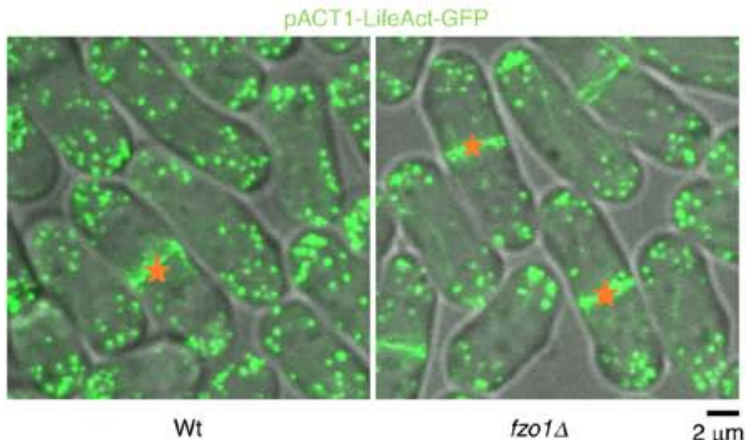

C

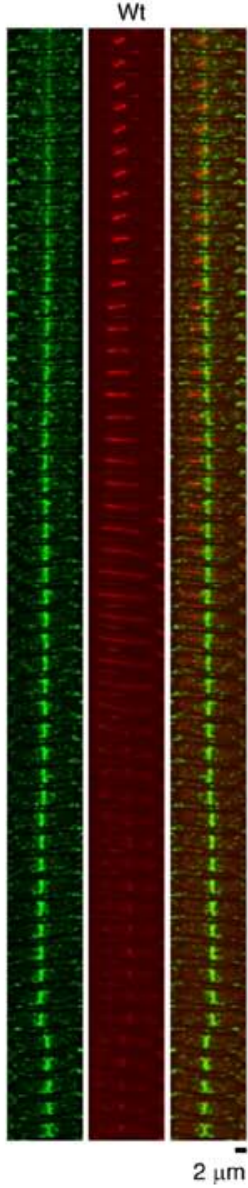

DACT1-LifeAct-GFP $\mathrm{mCH}-\mathrm{Atb} 2$

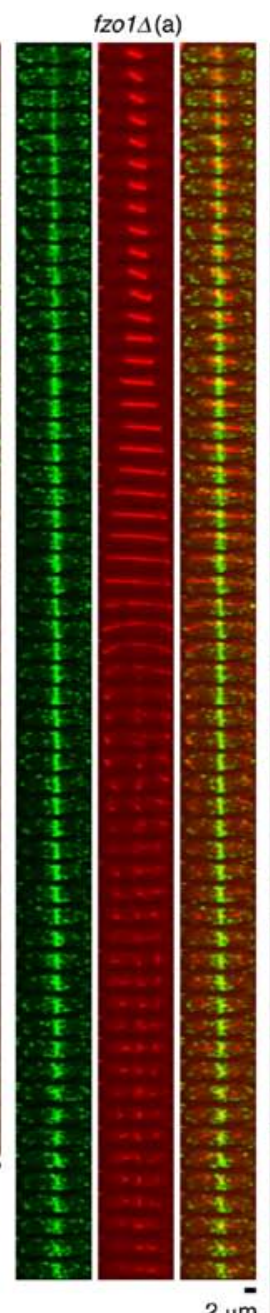

F

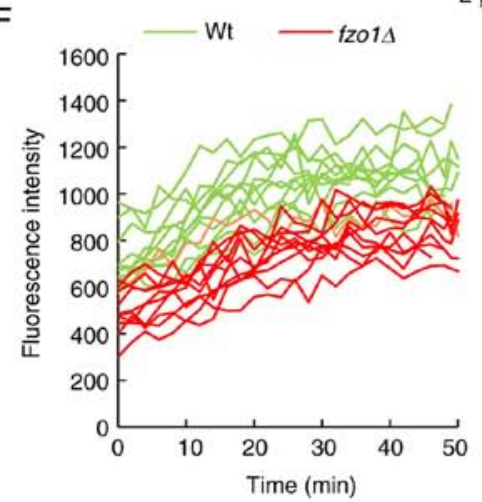

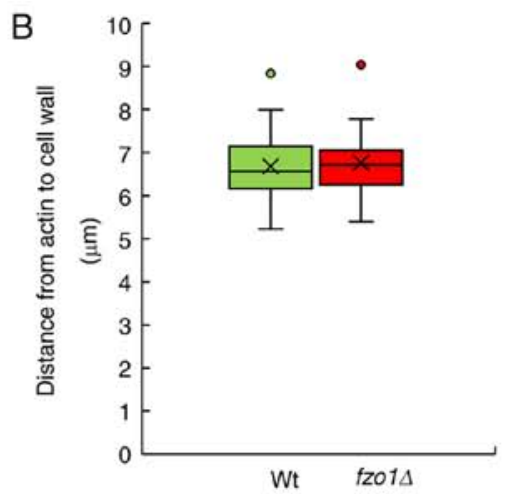

D

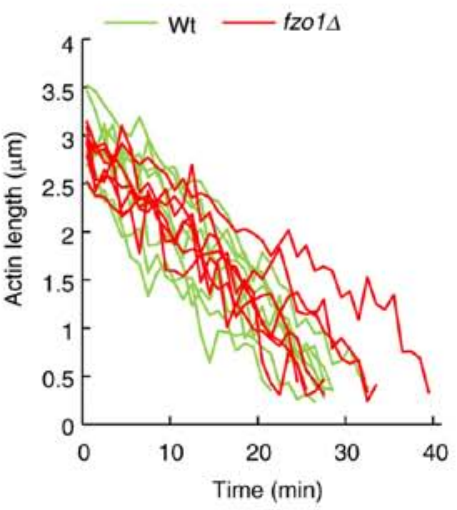

E

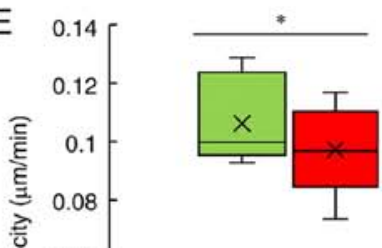

응

들

0.04

0.02

0

Wt tzo1s

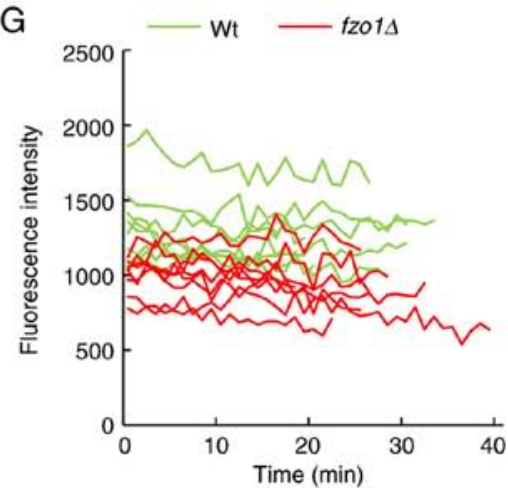

Figure 4. Effect of FZO1 gene deletion on actin in mitosis. (A) Actin morphology in Wt and $f z o 1 \Delta$ cells; $\star$, indicates the location of the splitting point. (B) Distance between splitting point and cell wall in Wt and $f z o 1 \Delta$ cells $(\mathrm{n}=20$ cells). (C) Actin kinetics in Wt and $f z o 1 \Delta$ cells during mitosis. Wt showed normal actin contraction; $f z o 1 \Delta$ cells exhibited (a) normal and (b) delayed contraction. (D) Actin contraction in Wt and $f z o 1 \Delta$ cells (Wt, $\mathrm{n}=8 \mathrm{cells} ; f z o 1, \mathrm{n}=7$ cells). (E) Actin contraction rate in Wt and $f z o l \Delta$ cells $(\mathrm{n}=7$ cells). (F) Fluorescence intensity from actin formation to spindle breakage in Wt and $f z o l \Delta$ cells $\left(\mathrm{n}=20\right.$ cells). (G) Fluorescence intensity from spindle breakage to actin disappearance in Wt and $f z o 1 \Delta$ cells ( $\mathrm{n}=20$ cells). ${ }^{*} \mathrm{P}<0.05$. $f z o$, fuzzy onions; $\mathrm{mCher}$ ry-Atb2, mCherry-tubulin $\alpha 2$; pACT1-LifeAct-GFP, actin-LifeAct-green fluorescent protein; Wt, wild-type. 
A
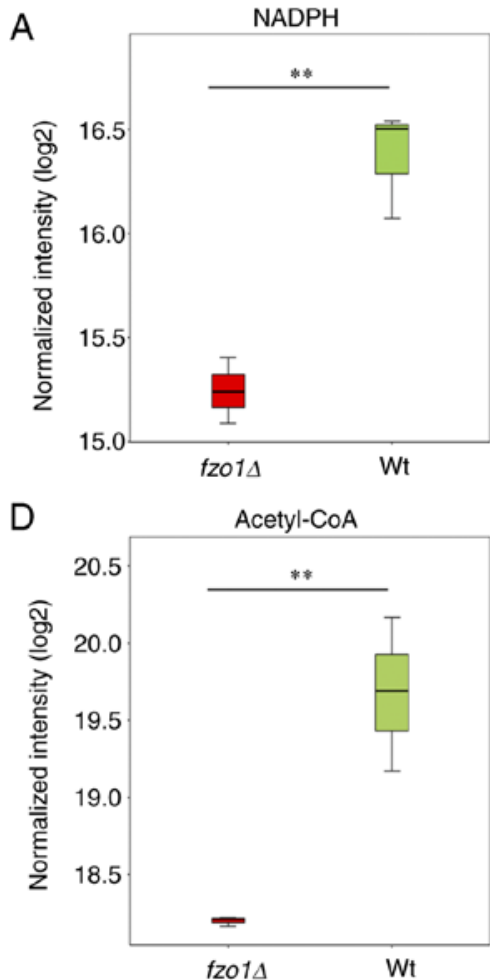

B

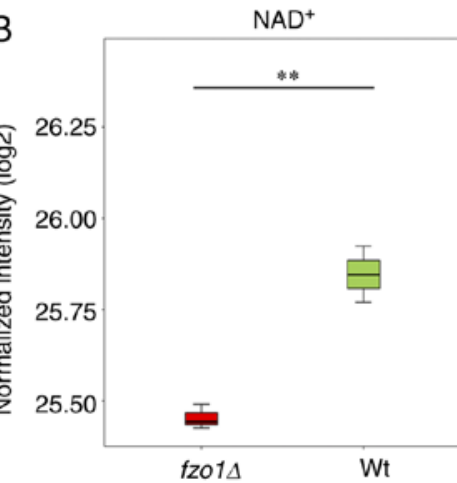

$\mathrm{E}$

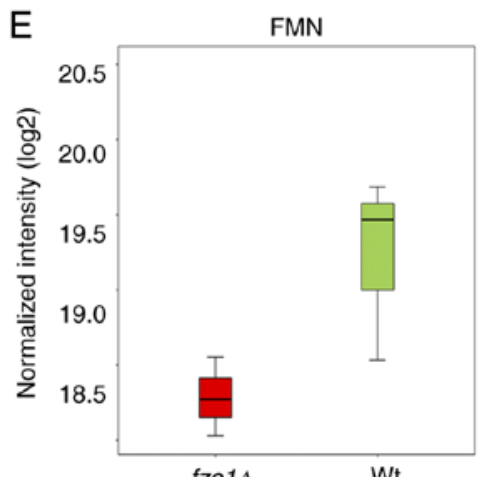

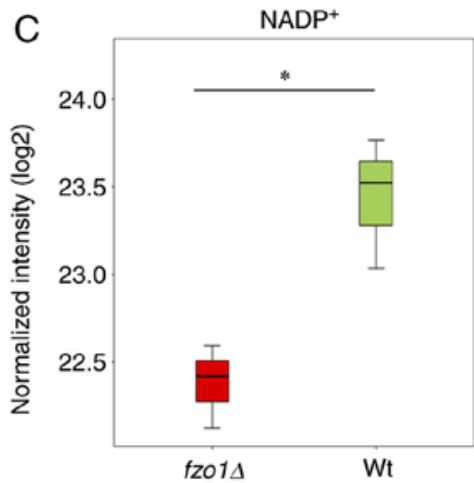

$\mathrm{F}$

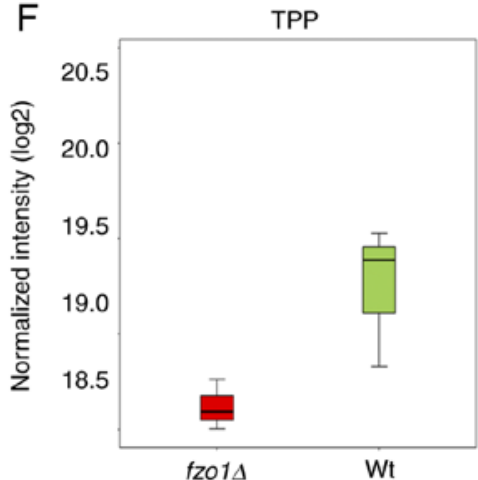

Figure 5. Effect of FZO1 gene deletion on coenzymes in energy metabolism. Relative contents of (A) NADPH, (B) NAD ${ }^{+},(\mathrm{C}) \mathrm{NADP}^{+}$, (D) acetyl-CoA, (E) FMN and (F) TPP in Wt and $f z o 1 \Delta$ cells ( $\mathrm{n}=3$ experimental repeats). ${ }^{*} \mathrm{P}<0.05,{ }^{* *} \mathrm{P}<0.01$. Acetyl-CoA, acetyl coenzyme A; FMN, flavin mononucleotide; fzo, fuzzy onions; Hht2-GFP, histone H3-green fluorescent protein; mCherry Atb2, mCherry-tubulin $\alpha 2$; NAD, nicotinamide adenine dinucleotide; NADP/NADPH, nicotinamide adenine dinucleotide phosphate; TPP, thiamine pyrophosphate; Wt, wild-type.

were $23.55 \pm 0.47,17.17 \pm 0.40$ and $23.40 \pm 0.33$, respectively, whereas those in fzol $\Delta$ cells were $22.29 \pm 0.41,16.09 \pm 0.17$ and $21.84 \pm 0.24$, respectively; these three intermediate metabolites were found in significantly lower levels in $f z o l \Delta$ cells compared with in wild-type cells $(\mathrm{P}<0.05$; Fig. $6 \mathrm{~A}$, $\mathrm{B}$ and D). Additionally, the relative contents of $c i s$-aconitate were significantly reduced in fzol $\Delta$ cells compared with in wild-type cells $(\mathrm{P}<0.01$; Fig. $6 \mathrm{C})$. The results indicated that FZO1 gene deletion affected the production of tricarboxylic acid cycle and glycolysis intermediates. There were not significant differences in the levels of other analyzed intermediates, including $\alpha$-ketoglutarate, oxaloacetate and photoshoenolpyruvate (Fig. 6E-L).

Effect of FZO1 gene deletion on energy in energy metabolism. The aim of cellular energy metabolism is to provide energy for cell growth and division. The results revealed that the relative contents of adenosine triphosphate (ATP), guanosine triphosphate (GTP), adenosine diphosphate (ADP) and adenosine monophosphate (AMP) in wild-type cells were 21.02 \pm 0.17 , $16.95 \pm 0.29,24.79 \pm 0.41$ and $26.35 \pm 0.12$, respectively, whereas the relative contents of those products in fzol $\Delta$ cells were $20.74 \pm 0.12,16.70 \pm 0.16,24.36 \pm 0.26$ and $26.34 \pm 0.02$, respectively cells (Fig. 7A-D). Of note, the contents of guanosine monophosphate (GMP) and guanosine diphosphate (GDP) in wild-type cells $(25.07 \pm 0.27$ and $20.98 \pm 0.14$, respectively) were significantly increased compared with those in $f z o l \Delta$ cells $(24.28 \pm 0.17$ and 20.45 \pm 0.19 , respectively; $\mathrm{P}<0.05$; Fig. 7E and F). The results suggested suggested that FZO1 gene deletion affected the production of GMP and GDP, without significantly affecting GTP and ATP production, in yeast cells.

\section{Discussion}

Metaphase is the stage of mitosis in which chromosomes attach to bipolar spindles and segregate directionally at anaphase (20). MTs and their related motors play an important role in nuclear migration, cell division, polarity and sexual reproduction (15). In different cell types, the metaphase spindle has a characteristic constant length (21). The present study showed that the FZO1 gene deletion can affect the growth rate and duration of spindle activity at the metaphase and anaphase. Additionally, spindle MT organization differed in fzol $\Delta$ cells compared with wild-type cells. Spindle length in metaphase is regulated by pulling and pushing forces produced by spindle MTs, as well as their interactions with motors and MT-associated proteins (MAPs) (15). Spindle length is important for the fidelity of chromosome segregation, as in the metaphase, cells with shorter or longer spindles than the normal length, which may occur due to inhibition or deletion of mitotic motors or MAPs, exhibit chromosome segregation defects (21). However, the present study did not involve the inhibition or deletion of mitotic motors or MAPs. Therefore, it is proposed that the loss of FZO1 results in mitochondrial dynamics deficiencies, which may contribute to spindle maintenance deficiencies and abnormal spindle breakage in the anaphase.

When fusion is dominant, mitochondria exist in the form of interconnected filaments; when division is dominant, mitochondria exist in the form of isolated dots (6). Mitomycin 
A
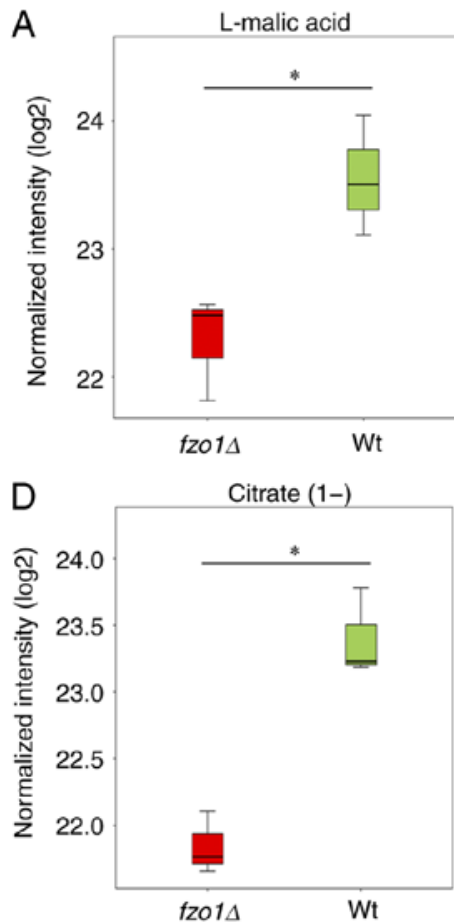

G

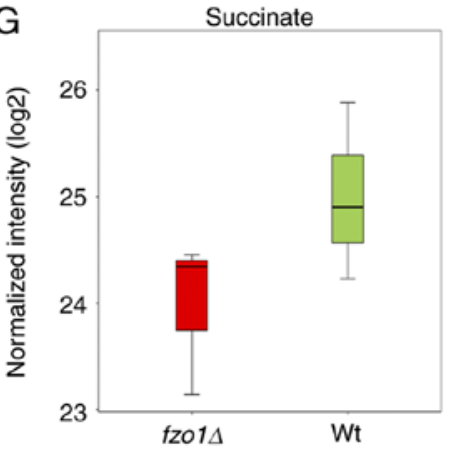

$\mathrm{J}$

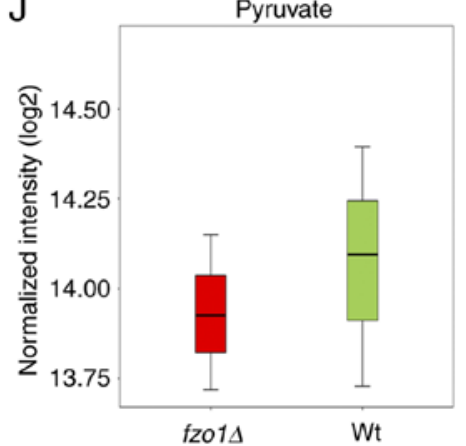

M

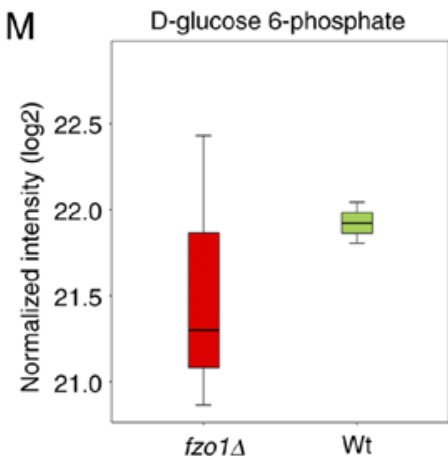

B

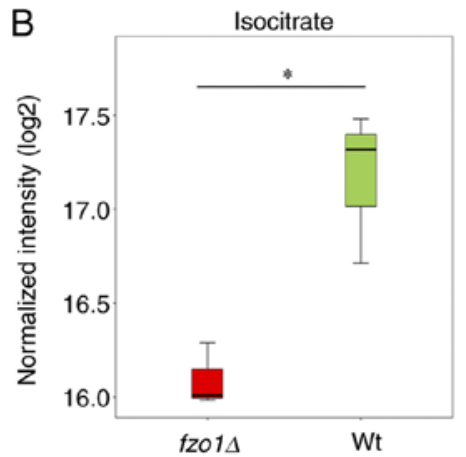

E
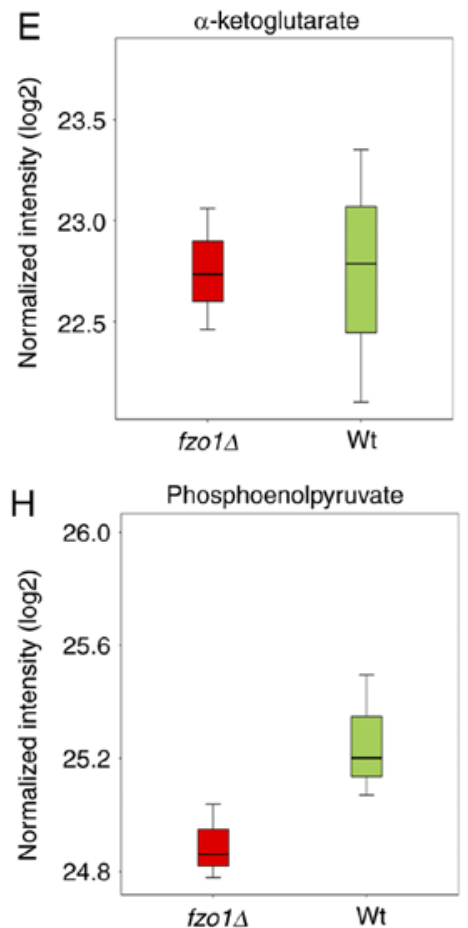

K D-fructose 1,6-bisphosphate

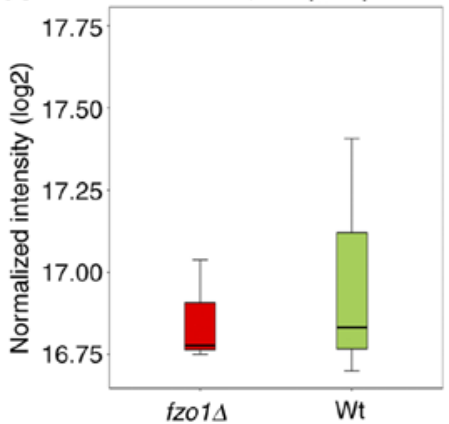

N Dihydroxyacetone phosphate

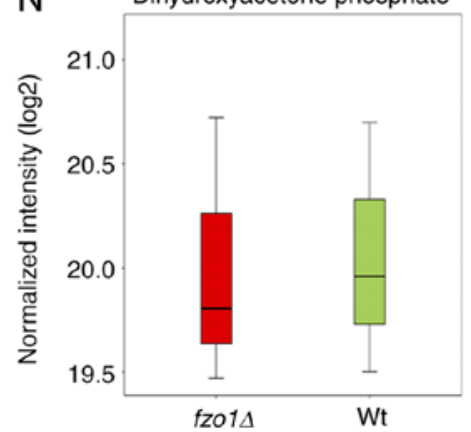

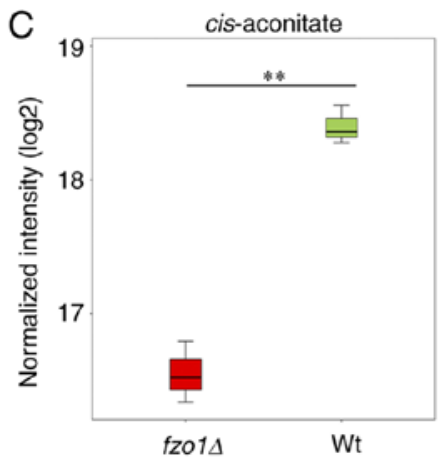

F
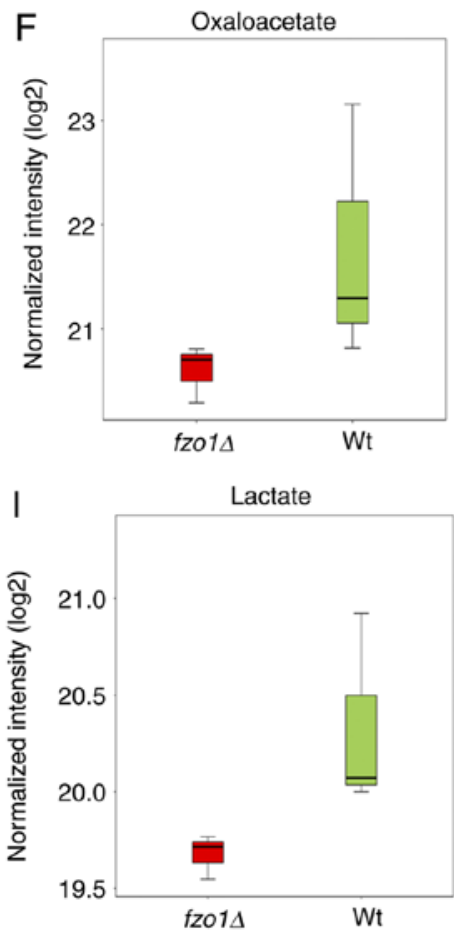

L $\quad \beta$-D-fructose 6-phosphate

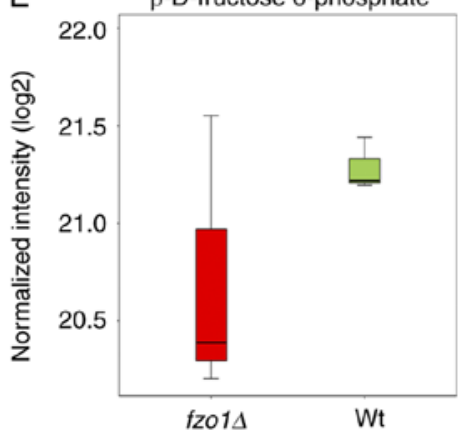

$\mathrm{O}$ Fumarate

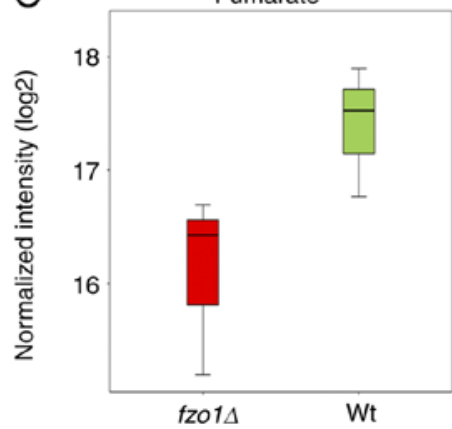

Figure 6. Effect of FZO1 gene deletion on intermediate metabolites of energy metabolism. Relative contents of (A) L-malic acid, (B) isocitrate, (C) cis-aconitate, (D) citrate(1-), (E) $\alpha$-ketoglutarate, (F) oxaloacetate, (G) succinate, (H) phosphoenolpyruvate, (I) lactate, (J) pyruvate, (K) D-fructose 1,6-bisphosphate, (L) $\beta$-D-fructose 6-phosphate, (M) D-glucose 6-phosphate, (N) dihydroxyacetone phosphate and (O) fumarate in Wt and fzol $\Delta$ cells ( $\mathrm{n}=3$ experimental repeat). ${ }^{*} \mathrm{P}<0.05,{ }^{* *} \mathrm{P}<0.01$. fzo, fuzzy onions; Wt, wild-type. 

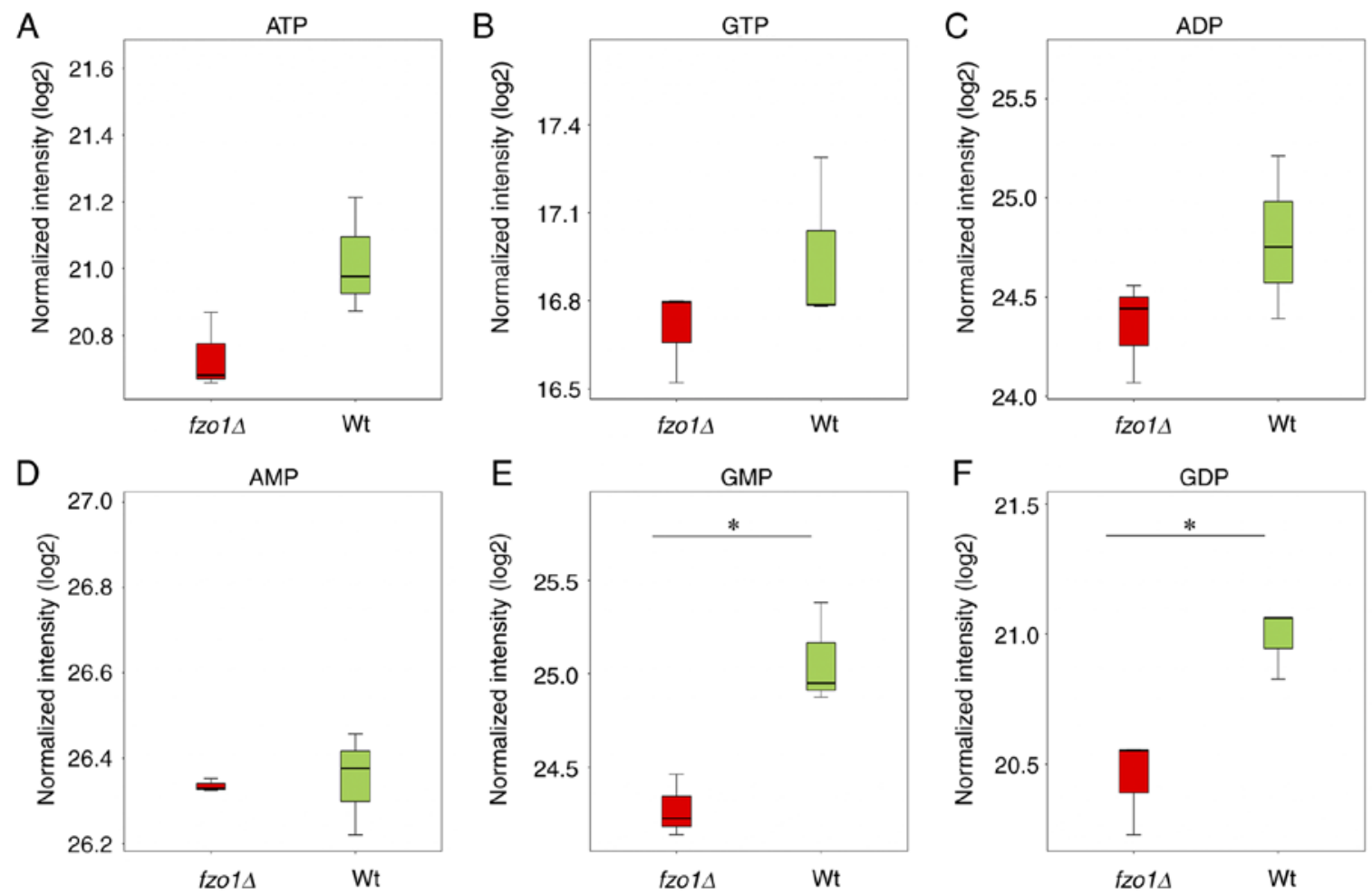

Figure 7. Effect of $F Z O 1$ gene deletion on energy production. Relative contents of (A) ATP, (B) GTP, (C) ADP, (D) AMP, (E) GMP and (F) GDP in Wt and $f z o l \Delta$ cells ( $\mathrm{n}=3$ experimental repeat). " $\mathrm{P}<0.05$. ADP, adenosine diphosphate; AMP, adenosine monophosphate; ATP, adenosine triphosphate; GDP, guanosine diphosphate; GMP, guanosine monophosphate; GTP, guanosine triphosphate; fzo, fuzzy onions; Wt, wild-type.

fusion protein (Mfn)1/2, Opa1 and Drp-1 are the main regulators of mitochondrial morphology (22). Mfn1 is a target of that can regulate the fusion of mitochondria by altering protein conformations (23). Opa1 is a GTP enzyme-related protein; it possesses a mitochondrial targeting sequence, which can guide proteins into the inter intimal and mitochondrial cristae (24). It regulates cytochrome $c$ and mitochondrial function by regulating and reshaping the shape of mitochondrial cristae (23). There are various types of mitochondrial dysfunction observed in Opal mutant cells, including mitochondrial cristae structural disorder, changes in mitochondrial network dynamics, cell proliferation deficiencies and respiratory capacity deficiencies (25). Drp-1 is a pro-fission molecule, which also participates in the remodeling of cytochrome $c$; Drp-1 deletion can affect mitochondrion fission and function (26), which is also fatal to embryo development (27). The fusion of the mitochondrial OM is regulated by the $\mathrm{FZOI}$ gene (6). In the present study, the mitochondrial morphology results indicated that the mitochondria were fragmented and tubular in wild-type cells, but existed in a state of accumulation in fzol $\Delta$ cells, which consistent with previous results (28).

In the process of energy production in mitochondria, abnormalities in coenzyme activity or intermediate metabolites such as $\mathrm{NADPH}, \mathrm{NAD}^{+}, \mathrm{NADP}^{+}$and acetyl-CoA may lead to cellular dysfunction. Decreased $\mathrm{NAD}^{+}$content may lead to nuclear and mitochondrial dysfunction, and is associated with numerous age-related diseases, such as Alzheimer's disease (29). Acetyl-CoA, as a carbon source consumed during oxidation in the dicarboxylic acid cycle, is one of the most important substrates in the tricarboxylic acid cycle (30). Alterations in acetyl-CoA levels affect the activity of citrate(1-) synthetase (31). Acetyl-CoA not only plays an important role in the tricarboxylic acid cycle, but also regulates the function and adaptability of neurons and non-neuronal brain cells (31). Intermediate metabolites in energy metabolism also play important roles in physiological and biochemical processes. For example, citric acid and L-malic acid are important intermediates in the tricarboxylic acid cycle, and have protective effects on myocardial ischemia-reperfusion injury (32); the potential mechanism may be associated with anti-inflammatory and anti-platelet aggregation actions, alongside direct myocardial protection (32). Isocitrate has a role in treating acute inflammatory anemia in mouse models (33). In the present study, it was shown that the relative contents of NADPH, $\mathrm{NAD}^{+}, \mathrm{NADP}^{+}$and acetyl-CoA in fzol $\Delta$ cells were significantly reduced compared with in wild-type cells. Additionally, relative levels of intermediate metabolites including L-malic acid, cis-aconitate, citrate(1-) and isocitrate were significantly reduced in fzol $\Delta$ cells compared with in wild-type cells. These results indicated that the relative content of important coenzymes and intermediate metabolites involved in the tricarboxylic acid cycle were substantially affected by the fzol $\Delta$ mutation.

The production of mitochondrial energy is essential for cell division, as well as other basic functions in the cell, including the regulation of cell volume, solute concentration and cellular architecture (34). At different stages of the cell cycle, energy levels vary, indicating that there is a relationship between energy abundance and the ability of cells to enter the new cell cycle, which supports the hypothesis that mitochondria play a critical role in the regulation of cell cycle progression (35). 
The specific mechanism connecting cell cycle regulation and mitochondria is not clear; studies have shown that low-energy cell cycle checkpoints regulate energy capacity before further rounds of cell division (36). Although there are reports that abnormal mitochondrion division and fusion cause the mitochondrial network to become scattered, leading to deficiencies in ATP production (37), in the present study, the relative contents of ATP, GTP, ADP and AMP were not significantly different between wild-type and fzol $\Delta$ cells. Conversely, the relative contents of GMP and GDP in fzol $\Delta$ cells were significant reduced compared with in wild-type cells.

The present study indicated that the loss of $\mathrm{FZOl}$ gene resulted in mitochondrial dynamics deficiencies, leading to deficiencies in spindle maintenance, chromosome segregation, spindle breakage, actin contraction, and coenzyme and intermediate metabolite levels. However, there is much further research required to fully understand how FZO1 regulates MT, chromosome and actin dynamics.

\section{Acknowledgements}

The authors wish to thank the Associate Professor Phong Tran (University of Pennsylvania) for donating yeast strains, and Shanghai Applied Protein Technology Co., Ltd for analyzing the liquid chromatography-mass spectrometry data.

\section{Funding}

This study was supported by the Sichuan Province Science and Technology Support Project (grant nos. 2018NZ0055, 2018JY0087 and 16cZ0018), the Nanchong City Science and Technology Project (grant no. 16YFZJ0043), the China West Normal University Science and Technology Program (grant nos.cXTd2017-3,17Yc136,17Yc328, 17Yc329and 17c039) and China Scholarship Council (grant nos. 201708510006 and 201708510007).

\section{Availability of data and materials}

The datasets used and/or analyzed during the current study are available from the corresponding author on reasonable request.

\section{Authors' contributions}

YH conceived and designed the experiments of the present study. YH, XD, RY and XT performed the experiments and acquired data. YH and RY drafted the manuscript and revised it critically. All authors read and approved the final manuscript.

\section{Ethics approval and consent to participate}

Not applicable.

\section{Patient consent for publication}

Not applicable.

\section{Competing interests}

The authors declare that they have no competing interests.

\section{References}

1. Bohnert M, Pfanner $\mathrm{N}$ and van der Laan $\mathrm{M}$ : Mitochondrial machineries for insertion of membrane proteins. Curr Opin Struct Biol 33: 92-102, 2015.

2. Jeong SY and Seol DW: The role of mitochondria in apoptosis. BMB Rep 41: 11-22, 2008.

3. Lackner LL: Shaping the dynamic mitochondrial network. BMC Biol 12: 35, 2014.

4. El-Hattab AW, Suleiman J, Almannai M and Scaglia F: Mitochondrial dynamics: Biological roles, molecular machinery, and related diseases. Mol Genet Metab 125: 315-321, 2018.

5. Hermann GJ, Thatcher JW, Mills JP, Hales KG, Fuller MT, Nunnari J and Shaw JM: Mitochondrial fusion in yeast requires the transmembrane GTPase Fzolp. J Cell Biol 143: 359-373, 1998.

6. Moore AS, Wong YC, Simpson CL and Holzbaur ELF: Dynamic actin cycling through mitochondrial subpopulations locally regulates the fission-fusion balance within mitochondrial networks. Nat Commun 7: 12886, 2016.

7. Harder Z, Zunino R and McBride H: Sumol conjugates mitochondrial substrates and participates in mitochondrial fission. Curr Biol 14: 340-345, 2004.

8. Hales KG and Fuller MT: Developmentally regulated mitochondrial fusion mediated by a conserved, novel, predicted GTPase. Cell 90: 121-129, 1997.

9. Rapaport D, Brunner M, Neupert W and Westermann B: Fzolp is a mitochondrial outer membrane protein essential for the biogenesis of functional mitochondria insaccharomyces cerevisiae. J Biol Chem 273: 20150-20155, 1998.

10. Santos A, Wernersson R and Jensen LJ: Cyclebase 3.0: A multi-organism database on cell-cycle regulation and phenotypes. Nucleic Acids Res 43: D1140-D1144, 2015.

11. Li C, Bai J, Hao X, Zhang S, Hu Y, Zhang X, Yuan W, Hu L, Cheng T, Zetterberg A, et al: Multi-gene fluorescence in situ hybridization to detect cell cycle gene copy number aberrations in young breast cancer patients. Cell Cycle 13: 1299-1305, 2014.

12. Gómez EB and Forsburg SL: Analysis of the fission yeast schizosaccharomyces pombe cell cycle. Methods Mol Biol 241: 93-111, 2004.

13. Forsburg SL and Rhind N: Basic methods for fission yeast. Yeast 23: 173-183, 2006.

14. Tran PT, Paoletti A and Chang F: Imaging green fluorescent protein fusions in living fission yeast cells. Methods 33: 220-225, 2004.

15. Rincon SA, Lamson A, Blackwell R, Syrovatkina V, Fraisier V, Paoletti A, Betterton MD and Tran PT: Kinesin-5-independent mitotic spindle assembly requires the antiparallel microtubule crosslinker Ase1 in fission yeast. Nat Commun 8: 15286, 2017.

16. Okada S, Leda M, Hanna J, Savage NS, Bi E and Goryachev AB: Daughter cell identity emerges from the interplay of Cdc42, septins, and exocytosis. Dev Cell 26: 148-161, 2013.

17. Alieva RR, Belogurova NV, Petrova AS and Kudryasheva NS: Effects of alcohols on fluorescence intensity and color of a discharged-obelin-based biomarker. Anal Bioanal Chem 406: 2965-2974, 2014

18. Lee ME, Rusin SF, Jenkins N, Kettenbach AN and Moseley JB: Mechanisms connecting the conserved protein kinases ssp1, kin1, and pom1 in fission yeast cell polarity and division. Curr Biol 28: 84-92. e4, 2018.

19. Strickland M and Stoll EA: Metabolic reprogramming in glioma. Front Cell Dev Biol 5: 43, 2017.

20. Schalch T and Steiner FA: Structure of centromere chromatin: From nucleosome to chromosomal architecture. Chromosoma 126: 443-455, 2017.

21. Syrovatkina V, Fu C and Tran PT: Antagonistic spindle motors and MAPs regulate metaphase spindle length and chromosome segregation. Currt Biol 23: 2423-2429, 2013.

22. Kim J and Cheong JH: Role of mitochondria-cytoskeleton interactions in the regulation of mitochondrial structure and function in cancer stem cells. Cells 9: 1691, 2020.

23. Pyakurel A, Savoia C, Hess D and Scorrano L: Extracellular regulated kinase phosphorylates mitofusin 1 to control mitochondrial morphology and apoptosis. Mol Cell 58: 244-254, 2015.

24. Del Dotto V, Fogazza M, Lenaers G, Rugolo M, Carelli V and Zanna C: OPA1: How much do we know to approach therapy? Pharmacol Res 131: 199-210, 2018.

25. Del Dotto V, Mishra P, Vidoni S, Fogazza M, Maresca A, Caporali L, McCaffery JM, Cappelletti M, Baruffini E, Lenaers G, et al: OPA1 isoforms in the hierarchical organization of mitochondrial functions. Cell Rep 19: 2557-2571, 2017. 
26. Milani M, Byrne DP, Greaves G, Butterworth M, Cohen GM, Eyers PA and Varadarajan S: DRP-1 is required for BH3 mimetic-mediated mitochondrial fragmentation and apoptosis. Cell Death Dis 8: e2552, 2017.

27. Ishihara N, Nomura M, Jofuku A, Kato H, Suzuki SO, Masuda K, Otera H, Nakanishi Y, Nonaka I, Goto YI, et al: Mitochondrial fission factor Drpl is essential for embryonic development and synapse formation in mice. Nat Cell Biol 11: 958-966, 2009.

28. Neutzner A and Youle RJ: Instability of the mitofusin Fzol regulates mitochondrial morphology during the mating response of the yeast saccharomyces cerevisiae. J Biol Chem 280: 18598-18603, 2005.

29. Xiao W, Wang RS, Handy DE and Loscalzo J: NAD(H) and NADP $(H)$ redox couples and cellular energy metabolism. Antioxid Redox Signal 28: 251-272, 2018.

30. Pietrocola F, Galluzzi L, Bravo-San Pedro JM, Madeo F and Kroemer G: Acetyl coenzyme a: A central metabolite and second messenger. Cell Metab 21: 805-821, 2015.

31. Ronowska A, Szutowicz A, Bielarczyk H, Gul-Hinc S, Klimaszewska-Łata J, Dyś A, Zyśk M and Jankowska-Kulawy A: The regulatory effects of acetyl-CoA distribution in the healthy and diseased brain. Front Cell Neurosci 12: 169, 2018.
32. Tang X, Liu J, Dong W, Li P, Li L, Lin C, Zheng Y, Hou J and Dan L: The cardioprotective effects of citric acid and L-malic acid on myocardial ischemia/reperfusion injury. Evid Based Complement Alternat Med 2013: 820695, 2013.

33. Kim A, Fung E, Parikh SG, Gabayan V, Nemeth E and Ganz T: Isocitrate treatment of acute anemia of inflammation in a mouse model. Blood Cells Mol Dis 56: 31-36, 2016.

34. Sweet S and Singh G: Changes in mitochondrial mass, membrane potential, and cellular adenosine triphosphate content during the cell cycle of human leukemic (hl-60) cells. J Cell Physiol 180: 91-96, 1999

35. Lopez-Mejia IC and Fajas L: Cell cycle regulation of mitochondrial function. Curr Opin Cell Biol 33: 19-25, 2015.

36. Salazar-Roa M and Malumbres M: Fueling the cell division cycle. Trends Cell Biol 27: 69-81, 2017.

37. Bartolák-Suki E, Imsirovic J, Nishibori Y, Krishnan R and Suki B: Regulation of mitochondrial structure and dynamics by the cytoskeleton and mechanical factors. Int J Mol Sci 18: 1812, 2017.

(i) 9 This work is licensed under a Creative Commons Attribution-NonCommercial-NoDerivatives 4.0 International (CC BY-NC-ND 4.0) License. 